\title{
PENGGUNAAN MEDIA PAPAN PUZZLE DALAM MENGENAL ANGKA
}

\section{USE OF PUZZLE BOARD MEDIA IN RECOGNIZING NUMBERS}

\author{
Seventina Nurul Hidayah ${ }^{1}$, Nilatul Izah $^{2}$, Iroma Maulida ${ }^{3}$ \\ ${ }^{1,2,3)}$ Program Studi D III Kebidanan Politeknik Harapan Bersama \\ Email : seventinanurulhidayah@gmail.com
}

\begin{abstract}
Getting to know numbers is one of the mandatory lessons for preschoolers. Parents should provide learning media according to their needs. One of the APE identifiers in the form of interesting snail puzzles can introduce numbers symbols to early childhood. This study aims to determine the objective conditions of the ability to recognize numbers, know the steps in the application of the snail puzzle media. This type of research is classroom action research (Classroom Action Research). The research subjects were gawai addicts students at Tegal Homeschooling ABCD. The design of the research through the stages of compiling planning (plan), implementation and observation (act and observe) and reflection (reflect). The results showed that children are interested in learning to recognize numbers with slug APE puzzles and increased numbers recognition skills, it is expected that schools add more interesting interactive media so that they can contribute to improving children's intelligence.
\end{abstract}

Keywords : Puzzle Board, Numbers, Preschool Kids

\begin{abstract}
Abstrak: penggunaan media papan puzzle dalam mengenal angka. Mengenal angka salah satu mata ajar wajib untuk anak prasekolah. Orang tua perlu memberikan media ajar sesuai kebutuhan. Tetapi di era sekarang sering ditemui orang tua yang membelikan gawai. Padahal anak pada fase perkembangan dan belajar yang terbaik adalah dengan benda nyata. Salah satu APE dalam mengenalkan angka berbentuk papan puzzle menarik ini dapat mengenalkan simbol angka kepada anak usia dini. Penelitian ini bertujuan untuk mengetahui kondisi objektif kemampuan mengenal angka, mengetahui langkah-langkah penerapan media papan puzzle.Jenis penelitian ini adalah penelitian tindakan kelas (Classroom ActionResearch). Subyek penelitian adalah siswa pecandu gawai di Homeschooling ABCD kota Tegal. Desain penelitian melalui tahapan menyusun perencanaan (plan),pelaksanaan dan pengamatan (act and observe) dan refleksi (reflect). Hasil penelitian didapatkan bahwa anak tertarik belajar mengenal angka dengan APE papan puzzle dan meningkat kemampuan pengenalan angkanya, diharapkan sekolah menambah media interaktif yang lebih menarik sehingga dapat memberikan kontribusi terhadap peningkatan kecerdasan anak.
\end{abstract}

Kata Kunci : Papan Puzzle, Angka, Anak Pra Sekolah

\section{PENDAHULUAN}

Mengenal angka merupakan salah satu pelajaran wajib untuk anak prasekolah. Orang tua seharusnya memberikan media belajar untuk anak sesuai kebutuhannya. Tetapi fenomena di masyarakat ternyata tidak demikian, di era modern saat ini sering sekali ditemukan orang tua yang membelikan gawai bagi anaknya yang baru memasuki periode perkembangan kecerdasan pada anak prasekoh yaitu usia dimana kemampuan sosial, kemampuan bahasa, koordinasi tangan dan mata, keseimbangan, dan rasa ingin tahu anak sedang mencapai puncaknya. Anak-anak lebih banyak menggunakan waktunya untuk bermain gawai dibandingkan dengan melakukan kegiatan fisik bersama 
teman (Lisiswanti R \& Nabila SI, 2017). Penggunaan gawai pada anak sudah menjadi hal yang biasa, bahkan Indonesia adalah salah satu negara yang menjadi pengguna gawai terbesar. Berdasarkan penelitian yang dilakukan oleh Ismanto dan Onibala menunjukkan bahwa anak-anak yang terbiasa bermain gawai, maka mereka akan lebih banyak menghabiskan waktu untuk hal itu. (Laili U, 2017). Berdasarkan penelitian yang dilakukan oleh Gunawan (2017) diketahui bahwa Indonesia adalah negara yang memiliki pengguna sosial media yang paling aktif di Asia. Indonesia memiliki 79,7\% user aktif di sosial media mengalahkan Filipina 78\%, Malaysia 72\%, Cina 67\%. Di Indonesia penggunaan media gawai pada anak berusia 5 tahun yaitu $38 \%$ pada tahun 2011, dan meningkat menjadi $72 \%$ pada tahun 2013, pada tahun 2015 ada peningkatan yaitu 80\%. Anak banyak menggunakan gawai sebagai sarana bermain, $23 \%$ orang tua yang memiliki anak berusia 5 tahun mengaku bahwa anak-anak mereka gemar menggunakan gawai, sedangkan dari $82 \%$ orang tua melaporkan bahwa mereka online setidaknya sekali dalam seminggu. Penggunaan gawai dikalangan anak-anak semakin memprihatinkan dan tentu memiliki dampak negatif terhadap tumbuh kembang. (Warisyah Y, 2015)

Peran orang tua yang dulunya sebagai teman bermain bagi anaknya sekarang tergantikan oleh gawai. Banyak alasan yang dikemukakan antara lain agar orang tua lebih leluasa beraktivitas tanpa perlu terus menerus mendampingi anaknya. Namun tak banyak orang tua menyadari bahaya yang mengintai anak akibat aktifitas berlebihan menggunakan gawai. Bermain gawai dalam durasi yang panjang dan dilakukan setiap hari secara kontinyu, bisa membuat anak berkembang ke arah pribadi yang antisosial. Hasil survey yang telah dilakukan peneliti di Homeschooling ABCD Kota Tegal pada tanggal 9 Oktober 2019 terhadap 2 orang tua siswa yang berusia 5 tahun dengan hasil semua telah menggunakan gawai, dimana yang 1 anak masih menggunakan gawai milik orang tuanya sedangkan yang 1 anak menggunakan gawai milik sendiri. Dari keseluruhan orang tua tidak ada pengawasan atau aturan khusus dalam penggunaan gawai kecuali batas atau lama penggunaan. Kapasitas penggunaan rata rata 1-2 kali/ hari, lamanya 1-2 jam/hari, aplikasi yangdigunakan rata-rata menggunakangame dan youtube. Dari 2 anak tersebut mereka mulai menggunakan gawai rata rata dari usia 3 tahun. (Balitbang Kemenkes RI, 2013)

Alat permainan anak-anak yang kreatif, edukatif, yang memotivasi sekaligus sebagai ajang mereka untuk bersosialisasi seiring perkembangan jaman nampaknya mau tak mau mulai tergantikan dengan permainan-permainan modern yang bisa diakses melalui gawai. Fitur menarik yang ada di gawai dan penggunaan yang tidak terkontrol dapat membuat anak menjadi kecanduan gawai, padahal anak pada fase perkembangan belajar terbaik adalah dari benda nyata. (Daryanto, 2012)

Belajar hanya menggunakan modul angka dirasa lebih cepat bosan, kurang termotivasi belajar dan masih mengalami kesulitan terutama pada belajar menulis angka. Menurut guru, sebagian anakanak sudah bisa memahami konsep dasar angka, tetapi untuk penulisannya anak-anak masih banyak yang kesulitan. Masalah belajar menulis angka seperti langkah penulisan angka yang mudah masih sering dibingungkan (misalnya harus menulis dari atas atau bawah), penulisan angka yang masih sering terbalik (misalnya angka 6 jadi 9) dan penulisan angka secara berurutan. Oleh karena itu penting menghadirkan media yang sesuai dengan karakteristik anak didik. Peneliti tertarik meneliti dengan judul penelitian "Pengenalan Angka dengan APE Papan puzzle untuk Anak Prasekolah Pecandu Gawai di Homescooling ABCD Kota Tegal".

Salah satu APE pengenal angka berbentuk papan puzzle menarik ini dapat mengenalkan simbol angka kepada anak usia dini. Manusia adalah makhluk bermain, sebagai makhluk bermain dapat tercermin dari perilaku manusia sejak lahir sampai akhir hayatnya. Agar permainan yang dimainkan memuat unsur pembelajaran, maka dikenalkan alat permainan edukatif bagi anak usia dini salah satunya adalah bentuk papan puzzle yang berguna untuk mengenalkan konsep angka sejak anak masih 
kecil. APE pengenal angka berbentuk siput ini sangat menarik karena terdiri dari berbagai warna. Anak perlu dikenalkan dan diajak bermain permainan tradisional (susun puzzle) sehingga mereka mempunyai pengalaman atau diingatkan lagi dengan pengalaman melakukan kegiatan fisik dengan teman sebaya, mereka juga bisa merasakan pengalaman sensori dan motorik sehingga mereka bisa merasakan sensasi asyiknya dan mengulangnya sehingga lambat laun permainan tradisional menjadi pilihan bermain. (Daryanto, 2012).

\section{METODE}

Penelitian dilakukan di Homeschooling ABCD kota Tegal yaitu pada bulan. Jenis Penelitian ini menggunakan Penelitian penelitian tindakan kelas (Classroom Action Research). Sampel diambil dengan cara purposive sampling, mengacu pada tujuan dan jenis penelitian. Sampel informan diperoleh secara purposive sampling, yang sesuai dengan jenis penelitian. (Moleong, Lexy J, 2013)

Informan pada penelitian adalah informan utama dan triangulasi. Informan utama adalah siswa pecandu gawai di Homeschooling ABCD kota Tegal. Jumlah informan utama sebanyak 10 anak. Informan triangulasinya adalah Koordinator Kelas. Pengambilan data dilakukan dengan teknik indepth interview sesuai dengan pedoman. Hasil wawancara direkam dan dibuat catatan lapangan. Untuk mencegah subyektifitas, peneliti memakai teknik triangulasi sumber.

\section{HASIL}

Penelitian ini mengambil lokasi di KB Homeschooling ABCD (Afektif, Behavior, Cognitive, Development) yang beralamat di Jalan Mliwis No.23 Pekauman Tegal Barat Kota Tegal di bawah naungan PKBM (Pusat Kegiatan Belajar Masyarakat) Budi Luhur. Untuk menjadi pelajar di Homeschooling ABCD tidak perlu memiliki kriteria khusus. Pelaksanaan homeschooling sesuai kebutuhan anak dan kondisi keluarga. Homeschooling lebih memberikan peluang untuk kemandirian dan kreativitas individual yang tidak didapatkan dalam model sekolah umum. Sekolah ini berjarak kurang lebih 100 meter sebelah Selatan jalan raya Pantura Kota Tegal. Sekolah ini berdiri sejak tahun 2008 dengan jumlah siswa pada saat itu hanya delapan anak berkebutuhan khusus semua.

Jumlah tenaga pengajar di sekolah ini sebanyak 7 orang dengan riwayat pendidikan S1 Psikologi, S1 Ocupasi Terapi dan D3 PAUD. Sarana yang dimiliki oleh sekolah ini diantaranya 6 ruang kelas, 1 Ruang Kepala Sekolah, 1 dapur dan 3 kamar mandi.

Penelitian ini diawali pada tanggal 7 Januari 2020, peneliti ke Homeschooling $A B C D$ dengan tujuan bertemu dengan Koordinator Kelas ABK Homeschooling ABCD, yakni Ibu Nur Aida Faizati, S.Psi untuk meminta izin mengadakan penelitian sekaligus mengantarkan surat izin penelitian dari P3M. Peneliti menyampaikan maksud kedatangan peneliti ke sekolah tersebut untuk melakukan penelitian terhadap Siswa ABK Pecandu Gawai di Homeschooling ABCD terkait pemahaman mereka dalam pembelajaran matematika khususnya dalam pengenalan angka 1 - 10 yang menjadi mata pelajaran utama bagi usia mereka. Ibu Aida menyambut baik maksud peneliti dan menyatakan bersedia membantu peneliti selama proses penelitian berlangsung. Pada kesempatan tersebut peneliti menyampaikan permohonan ijin kepada Bu Aida utuk melakukan observasi di kelas beliau. Peneliti juga menyampaikan sedikit gambaran tentang alur penelitian di kelas beliau. Namun peneliti tidak diijinkan masuk kelas dengan alasan bahwa konsentrasi dari siswa ABK akan terganggu apabila ada orang lain masuk kelas selain guru pendamping harian. 
Vol 10 No 2 Juli 2021 | Page 69-76

Sehingga dalam hal ini disepakati bahwa observasi langsung dilakukan oleh guru pendamping dan terkait kejelasan dari hasil observasi peneliti melakukan wawancara mendalam dengan guru pendamping yang di wakilkan langsung oleh Kepala Sekolah Homeschooling ABCD.

Penelitian dilakukan dalam tahapan yang berupa siklus pembelajaran. Dalam penelitian ini pembelajaran dilakukan dalam 1 siklus, yaitu Siklus I. Sebelum pelaksanaan Siklus I, dilakukan tahap perencanaan yang meliputi kegiatan sebagai berikut :

a) Peneliti bersama koordinator kelas menetapkan waktu dilakukannya penelitian tindakan kelas, yaitu hari Rabu 8 januari 2020

b) Peneliti menyusun Rencana Kegiatan Harian (RKH) yang akan digunakan guru sebagai acuan pelaksanaan pembelajaran, terutama kegiatan pengenalan angka dengan media puzzle. RKH yang akan dilakukan pada Siklus I ini terlampir.

c) Peneliti mempersiapkan papan puzzle yang digunakan dalam kegiatan pembelajaran, khususnya pada kegiatan pengenalan angka 1 - 10 .

d) Peneliti menyiapkan instrumen penilaian, yang terdiri dari lembar observasi aktivitas guru dalam pembelajaran, lembar observasi kemampuan anak menyebut angka 1 - 10 untuk setiap pertemuan di kelas yang digunakan untuk mengukur kemampuan anak dalam mengenal angka 1 - 10 .

e) Peneliti menyiapkan hp untuk mendokumentasikan aktivitas penelitian

Table 1. Lembar Observasi Aktivitas Guru dalam Kegiatan Meningkatkan Kemampuan Mengenal Angka 1 - 10 dengan Media Papan puzzle DI KB ABCD

\begin{tabular}{|c|c|c|c|}
\hline \multirow{2}{*}{ No } & \multirow{2}{*}{ Aspek yang diamati } & \multicolumn{2}{|c|}{ Jawab } \\
\hline & & $\mathbf{Y}$ & $\mathbf{T}$ \\
\hline 1 & Guru menyiapkan media pembelajaran & $\mathrm{v}$ & \\
\hline 2 & $\begin{array}{l}\text { Guru menyiapkan alat peraga untuk menjelaskan tentang angka (papan } \\
\text { puzzle) }\end{array}$ & $\mathrm{v}$ & \\
\hline 3 & Guru menjelaskan papan puzzle yang akan digunakan & $\mathrm{v}$ & \\
\hline 4 & Guru menjelaskan tujuan pembelajaran dengan menggunakan papan puzzle & $\mathrm{v}$ & \\
\hline 5 & Guru memberikan motivasi dengan kegiatan yang menarik pada anak & $\mathrm{v}$ & \\
\hline 6 & Guru memberikan kesempatan bertanya pada anak & $\mathrm{v}$ & \\
\hline 7 & $\begin{array}{l}\text { Guru memberikan kesempatan pada anak untuk beraktivitas dalam kegiatan } \\
\text { pengenalan angka }\end{array}$ & $\mathrm{v}$ & \\
\hline 8 & Guru mengajak anak berdiskusi hasil aktivitas kegiatan pengenalan angka & $\mathrm{v}$ & \\
\hline 9 & $\begin{array}{l}\text { Guru mengajak anak untuk menarik kesimpulan dari aktivitas pengenalan } \\
\text { angka yang sudah dilakukan }\end{array}$ & $\mathrm{v}$ & \\
\hline
\end{tabular}

Table 2. Lembar Observasi Kemampuan Anak Menyebut Angka 1 - 10 dengan Potongan Papan puzzle di KB ABCD (pra tindakan dan tindakan)

\begin{tabular}{|c|c|c|c|c|c|c|c|c|c|c|c|}
\hline \multirow[b]{2}{*}{ NO } & \multirow[b]{2}{*}{ NAMA } & \multicolumn{10}{|c|}{ ANGKA YANG DISEBUTKAN } \\
\hline & & 1 & 2 & 3 & 4 & 5 & 6 & 7 & 8 & 9 & $\mathbf{1 0}$ \\
\hline 1 & $A n . D 6 t h$ & $\mathrm{~V}$ & $\mathrm{~V}$ & $\mathrm{~V}$ & $\mathrm{x}$ & $\mathrm{X}$ & V & $\mathrm{V}$ & $\mathrm{x}$ & $\mathrm{V}$ & $\mathrm{V}$ \\
\hline 2 & An. F 5 th & $\mathrm{V}$ & $\mathrm{V}$ & $\mathrm{X}$ & $\mathrm{X}$ & $\mathrm{X}$ & V & V & $\mathrm{V}$ & $\mathrm{V}$ & $\mathrm{V}$ \\
\hline 3 & An. Ki 6 th & $\mathrm{x}$ & $\mathrm{v}$ & $\mathrm{v}$ & $\mathrm{v}$ & $\mathrm{x}$ & $\mathrm{x}$ & $\mathrm{v}$ & $\mathrm{x}$ & $\mathrm{x}$ & $\mathrm{x}$ \\
\hline 4 & An. La 4 th & $\mathrm{v}$ & $\mathrm{V}$ & $\mathrm{v}$ & $\mathrm{V}$ & $\mathrm{V}$ & V & $\mathrm{v}$ & $\mathrm{v}$ & $\mathrm{v}$ & $\mathrm{V}$ \\
\hline
\end{tabular}

\begin{tabular}{l|l} 
https://ejournal.umpri.ac.id/index.php/JIK & 72
\end{tabular} 
Vol 10 No 2 Juli 2021 | Page 69-76

\begin{tabular}{clcccccccccc}
\hline 5 & $A n . G u 7 t h$ & v & v & v & v & v & v & x & x & x & x \\
\hline 6 & $A n . B u 6 t h$ & v & v & v & x & v & v & v & v & x & v \\
\hline 7 & $A n . W e 7 t h$ & v & v & v & x & x & x & v & v & x & v \\
\hline 8 & $A n . Z$ Ze $7 t h$ & v & v & v & v & v & v & v & x & x & v \\
\hline 9 & $A n . P o 5 t h$ & v & v & v & v & v & v & x & x & x & v \\
\hline 10 & $A n . C i 7 t h$ & v & v & v & v & v & x & x & v & v & v \\
\hline
\end{tabular}

Dari hasil lembar observasi pengenalan angka 1 - 10 pratindakan didapatkan hasil bahwa nilai minimal 50 dan nilai maksimal 100 dan dari hasil penilaian berdasarkan rumus hasil nilai berdasarkan kriteria adalah 72 (baik).

\begin{tabular}{|c|c|c|c|c|c|c|c|c|c|c|c|}
\hline \multirow[b]{2}{*}{ NO } & \multirow[b]{2}{*}{ NAMA } & \multicolumn{10}{|c|}{ ANGKA YANG DISEBUTKAN } \\
\hline & & $\mathbf{1}$ & 2 & 3 & 4 & 5 & 6 & 7 & 8 & 9 & 10 \\
\hline 1 & An. D 6 th & $\mathrm{V}$ & $\mathrm{v}$ & $\mathrm{V}$ & $\mathrm{v}$ & $\mathrm{v}$ & $\mathrm{v}$ & $\mathrm{v}$ & $\mathrm{v}$ & $\mathrm{v}$ & $\mathrm{V}$ \\
\hline 2 & An. F 5 th & $\mathrm{v}$ & $\mathrm{V}$ & $\mathrm{V}$ & $\mathrm{v}$ & $\mathrm{v}$ & $\mathrm{V}$ & $\mathrm{V}$ & $\mathrm{v}$ & $\mathrm{v}$ & $\mathrm{V}$ \\
\hline 3 & An. Ki 6 th & $\mathrm{X}$ & $\mathrm{v}$ & $\mathrm{V}$ & $\mathrm{v}$ & $\mathrm{x}$ & $\mathrm{x}$ & $\mathrm{v}$ & $\mathrm{x}$ & $\mathrm{x}$ & $\mathrm{X}$ \\
\hline 4 & An. La 4 th & $\mathrm{V}$ & $\mathrm{V}$ & $\mathrm{V}$ & $\mathrm{V}$ & $\mathrm{V}$ & $\mathrm{V}$ & $\mathrm{V}$ & $\mathrm{V}$ & $\mathrm{V}$ & $\mathrm{V}$ \\
\hline 5 & An. Gu 7 th & $\mathrm{v}$ & $\mathrm{V}$ & $\mathrm{V}$ & $\mathrm{v}$ & $\mathrm{v}$ & $\mathrm{v}$ & $\mathrm{x}$ & $\mathrm{x}$ & $\mathrm{x}$ & $\mathrm{x}$ \\
\hline 6 & An. Bu 6 th & $\mathrm{v}$ & $\mathrm{V}$ & $\mathrm{V}$ & $\mathrm{v}$ & $\mathrm{v}$ & $\mathrm{v}$ & $\mathrm{V}$ & $\mathrm{v}$ & $\mathrm{v}$ & $\mathrm{V}$ \\
\hline 7 & An. We 7 th & $\mathrm{v}$ & $\mathrm{V}$ & $\mathrm{V}$ & $\mathrm{x}$ & $\mathrm{x}$ & $\mathrm{x}$ & $\mathrm{v}$ & $\mathrm{V}$ & $\mathrm{x}$ & $\mathrm{V}$ \\
\hline 8 & An. Ze 7 th & $\mathrm{v}$ & $\mathrm{V}$ & $\mathrm{V}$ & $\mathrm{V}$ & $\mathrm{v}$ & $\mathrm{V}$ & $\mathrm{V}$ & $\mathrm{v}$ & $\mathrm{v}$ & $\mathrm{V}$ \\
\hline 9 & An. Po 5 th & $\mathrm{V}$ & $\mathrm{V}$ & $\mathrm{V}$ & $\mathrm{V}$ & $\mathrm{V}$ & $\mathrm{V}$ & $\mathrm{V}$ & $\mathrm{V}$ & $\mathrm{V}$ & $\mathrm{V}$ \\
\hline 10 & An. Ci 7 th & $\mathrm{v}$ & $\mathrm{V}$ & $\mathrm{V}$ & $\mathrm{V}$ & $\mathrm{v}$ & $\mathrm{V}$ & $\mathrm{v}$ & $\mathrm{V}$ & $\mathrm{v}$ & $\mathrm{V}$ \\
\hline
\end{tabular}

Dari hasil lembar observasi pengenalan angka 1 - 10 didapatkan hasil bahwa nilai minimal 50 dan nilai maksimal 100 dan dari hasil penilaian berdasarkan rumus hasil nilai berdasarkan kriteria adalah 86 (sangat baik).

Table 3. Lembar Penilaian Kemampuan Anak Menempelkan Papan puzzle (pra tindakan dan tindakan)

\begin{tabular}{|c|c|c|c|c|c|c|c|c|c|c|}
\hline \multirow[t]{2}{*}{ NAMA } & \multicolumn{9}{|c|}{ KESESUAIAN } & \\
\hline & 1 & 2 & 3 & 4 & 5 & 6 & 7 & 8 & 9 & 10 \\
\hline An. Al 6 th & $\mathrm{V}$ & $\mathrm{V}$ & $\mathrm{V}$ & $\mathrm{V}$ & $\mathrm{V}$ & $\mathrm{v}$ & $\mathrm{v}$ & $\mathrm{v}$ & $\mathrm{v}$ & $\mathrm{v}$ \\
\hline An. Gi 5 th & $\mathrm{v}$ & $\mathrm{V}$ & $\mathrm{x}$ & $\mathrm{x}$ & $\mathrm{x}$ & $\mathrm{x}$ & $\mathrm{x}$ & $\mathrm{x}$ & $\mathrm{V}$ & $\mathrm{V}$ \\
\hline An. Di 6 th & $\mathrm{V}$ & $\mathrm{x}$ & $\mathrm{x}$ & $\mathrm{x}$ & $\mathrm{x}$ & $\mathrm{x}$ & $\mathrm{x}$ & $\mathrm{x}$ & $\mathrm{x}$ & $\mathrm{x}$ \\
\hline An. Qi 4 th & $\mathrm{V}$ & $\mathrm{V}$ & $\mathrm{v}$ & $\mathrm{x}$ & $\mathrm{x}$ & $\mathrm{x}$ & $\mathrm{x}$ & $\mathrm{v}$ & $\mathrm{V}$ & $\mathrm{v}$ \\
\hline An. Ai 7 th & $\mathrm{v}$ & $\mathrm{x}$ & $\mathrm{x}$ & $\mathrm{X}$ & $\mathrm{x}$ & $\mathrm{x}$ & $\mathrm{x}$ & $\mathrm{x}$ & $\mathrm{x}$ & $\mathrm{x}$ \\
\hline An. Ax 6 th & $\mathrm{v}$ & $\mathrm{V}$ & $\mathrm{v}$ & $\mathrm{v}$ & $\mathrm{v}$ & $\mathrm{v}$ & $\mathrm{v}$ & $\mathrm{v}$ & $\mathrm{v}$ & $\mathrm{v}$ \\
\hline An. Do 7 th & $\mathrm{V}$ & $\mathrm{V}$ & $\mathrm{V}$ & $\mathrm{V}$ & $\mathrm{V}$ & $\mathrm{V}$ & $\mathrm{v}$ & $\mathrm{V}$ & $\mathrm{V}$ & $\mathrm{V}$ \\
\hline An. Ar 7 th & $\mathrm{V}$ & $\mathrm{V}$ & $\mathrm{x}$ & $\mathrm{x}$ & $\mathrm{X}$ & $\mathrm{x}$ & $\mathrm{x}$ & $\mathrm{x}$ & $\mathrm{x}$ & $\mathrm{x}$ \\
\hline An. Al 5 th & $\mathrm{V}$ & $\mathrm{V}$ & $\mathrm{V}$ & $\mathrm{V}$ & $\mathrm{V}$ & $\mathrm{x}$ & $\mathrm{x}$ & $\mathrm{x}$ & $\mathrm{x}$ & $\mathrm{V}$ \\
\hline An. Az 7 th & $\mathrm{V}$ & $\mathrm{V}$ & $\mathrm{V}$ & $\mathrm{x}$ & $\mathrm{x}$ & $\mathrm{x}$ & $\mathrm{x}$ & $\mathrm{x}$ & $\mathrm{V}$ & $\mathrm{V}$ \\
\hline
\end{tabular}




\section{Vol 10 No 2 Juli 2021 | Page 69-76}

Dari hasil lembar observasi pengenalan angka 1 - 10 didapatkan hasil bahwa nilai minimal 50 dan nilai maksimal 100 dan dari hasil penilaian berdasarkan rumus hasil nilai berdasarkan kriteria adalah 54 (cukup).

\begin{tabular}{|c|c|c|c|c|c|c|c|c|c|c|}
\hline \multirow[t]{2}{*}{ NAMA } & \multicolumn{10}{|c|}{$\begin{array}{c}\text { KESESUAIAN } \\
\text { POTONGAN ANGKA YANG } \\
\text { DITEMPELKAN }\end{array}$} \\
\hline & 1 & 2 & 3 & 4 & 5 & 6 & 7 & 8 & 9 & 10 \\
\hline An. Al 6 th & $\mathrm{v}$ & $\mathrm{V}$ & $\mathrm{v}$ & $\mathrm{v}$ & V & $\mathrm{V}$ & $\mathrm{v}$ & $\mathrm{V}$ & $\mathrm{v}$ & $\mathrm{V}$ \\
\hline An. Gi 5 th & $\mathrm{v}$ & $\mathrm{V}$ & $\mathrm{v}$ & X & X & $\mathrm{X}$ & $\mathrm{x}$ & V & $\mathrm{V}$ & $\mathrm{V}$ \\
\hline An. Di 6 th & $\mathrm{v}$ & $\mathrm{x}$ & $\mathrm{x}$ & $\mathrm{x}$ & $\mathrm{X}$ & $\mathrm{x}$ & $\mathrm{x}$ & $\mathrm{x}$ & $\mathrm{x}$ & $\mathrm{x}$ \\
\hline An. Qi 4 th & $\mathrm{V}$ & $\mathrm{V}$ & $\mathrm{V}$ & $\mathrm{X}$ & $\mathrm{X}$ & $\mathrm{X}$ & $\mathrm{x}$ & V & $\mathrm{V}$ & $\mathrm{v}$ \\
\hline An. Ai 7 th & $\mathrm{v}$ & $\mathrm{X}$ & $\mathrm{X}$ & $\mathrm{X}$ & X & $\mathrm{X}$ & $\mathrm{X}$ & $\mathrm{X}$ & $\mathrm{X}$ & $\mathrm{X}$ \\
\hline An. Ax 6 th & $\mathrm{v}$ & $\mathrm{v}$ & $\mathrm{v}$ & $\mathrm{V}$ & V & $\mathrm{V}$ & $\mathrm{V}$ & V & $\mathrm{v}$ & $\mathrm{v}$ \\
\hline An. Do 7 th & $\mathrm{v}$ & $\mathrm{v}$ & $\mathrm{v}$ & $\mathrm{V}$ & V & $\mathrm{V}$ & $\mathrm{v}$ & $\mathrm{V}$ & $\mathrm{v}$ & $\mathrm{V}$ \\
\hline An. Ar 7 th & $\mathrm{v}$ & $\mathrm{v}$ & $\mathrm{x}$ & $\mathrm{x}$ & $\mathrm{x}$ & $\mathrm{x}$ & $\mathrm{x}$ & $\mathrm{x}$ & $\mathrm{x}$ & $\mathrm{x}$ \\
\hline An. Al 5 th & $\mathrm{v}$ & $\mathrm{v}$ & $\mathrm{v}$ & $\mathrm{v}$ & $\mathrm{V}$ & $\mathrm{V}$ & $\mathrm{V}$ & $\mathrm{V}$ & $\mathrm{V}$ & $\mathrm{v}$ \\
\hline An. Az 7 th & $\mathrm{v}$ & $\mathrm{v}$ & $\mathrm{v}$ & $\mathrm{v}$ & $\mathrm{v}$ & $\mathrm{V}$ & $\mathrm{v}$ & $\mathrm{v}$ & $\mathrm{v}$ & $\mathrm{V}$ \\
\hline
\end{tabular}

Dari hasil lembar observasi pengenalan angka 1 - 10 didapatkan hasil bahwa nilai minimal 50 dan nilai maksimal 100 dan dari hasil penilaian berdasarkan rumus hasil nilai berdasarkan kriteria adalah 66 (baik).

\section{PEMBAHASAN}

Hasil observasi didapatkan hasil: Homeschooling ABCD melaksanakan kegiatan belajar dari Senin - Kamis di kelas bersama guru pendamping kelas, sedangkan hari Jumat - Sabtu mereka mengikuti kegiatan outbond. Sekolah juga memiliki kerjasama dengan lembaga baik PMI, tempat rekreasi atau yang lainnya agar siswa dapat belajar Social Life. Anak berkebutuhan khusus (ABK) membutuhkan cara belajar yang lebih ekstra. Terutama dalam hal ini pemahaman terhadap matematika dasar yaitu dalam pengenalan angka (1 - 10) masih kurang. Hal ini senada dengan penuturan Bu Aida bahwa menurut beliau, pemahaman siswa saat masuk pertama masih rendah. Sebagian besar siswa belum mampu menyebutkan angka 1 - 10 dengan lancar, mereka hanya mengingat itupun dengan bantuan guru. Beberapa siswa juga mengalami kesulitan untuk menuliskan angka sehingga guru mensiasati menuliskan contoh angka di buku tulis kemudian siswa diminta menirukan. Sebagian dari baru bisa menghafal beberapa angka saja walaupun ada pula yang sudah mengenal 1 - 10 . Penyebabnya ingatan mereka yang lemah serta kurang mampu berkonsentrasi dalam belajar sehingga tidak jarang pelajaran yang baru mereka dapat mudah terlupakan.

Di sela pelaksanaan observasi, peneliti juga menanyakan cakupan materi matematika yang sudah disampaikan di kelas agar peneliti dapat menyiapkan pertayaan pemahaman untuk bahan wawancara yang sesuai dengan indikator kemampuan. Berdasarkan informasi beliau, materi matematika yang disampaikan di kelas masih seputar pengenalan angka.

Tanggal 6 januari 2020 peneliti menemui Bu Aida untuk meminta pertimbangan waktu pelaksanaan pengamatan dan wawancara dengan guru. Untuk waktu pelaksanaan wawancara, bu Aida menyerahkan kepada peneliti. 
Pada dasarnya pengenalan angka dengan media papan puzzle adalah mendekatkan anak pada obyek nyata. Media papan puzzle merupakan media yang lebih nyata dari media verbal (Indriana, 2011). Indriana mengemukakan pentingnya obyek nyata pada proses pembelajaran umur dini karena merupakan proses peralihan dari fase pra ke konkret operasional. Pada tahap ini anak akan belajar dengan baik dari benda konkret yang dapat diindera oleh anak. Puzzle melatih anak dengan cara mengingat urutan sesuai angka sehingga diharapkan ingatan anak mudah terasosiasi atau terhubung dengan angka yang ingin di ajarkan.

Selain pemilihan media yang sesuai, tidak kalah penting adalah menghilangkan hambatan psikologis anak. Rasa malu, cemas, minder dan takut merupakan hambatan emosi. Perlu didukung suasana nyaman dan kondusif yang akan membantu kelancaran belajar. Guru perlu berusaha membangun suasana seideal mungkin dalam mencapai tujuan yang diinginkan.

Pada akhir Siklus I telah terjadi peningkatan kemampuan anak yang cukup baik, baik dari kemampuan menyebut angka dan menempelkan puzzle. Kemampuan rata-rata anak pada saat pratindakan sebesar 72 meningkat menjadi 86 pada akhir Siklus I, kemampuan menempelkan puzzle sebesar 54 dan kemampuan menulis sebesar 66. Meskipun terjadi peningkatan, tetapi hasil belum mencapai indikator keberhasilan yang diinginkan. Setelah dilakukan refleksi, diperlukan langkah selanjutnya untuk merencanakan kegiatan agar mencapai hasil yang lebih baik.

Penelitian ini telah selesai dan tidak lagi peneliti lanjutkan ke siklus berikutnya. Ada beberapa temuan selama penelitian untuk dijadikaan dasar pengembangan penelitian selanjutnya. Beberapa hal tersebut adalah:

a. Anak jadi lebih mudah mengingat bentuk angka.

b. Anak tidak bosan karena penggunaan puzzle lebih variatif dan menyenangkan. Di samping itu, papan puzzle mudah untuk dikemas dalam bentuk permainan.

c. Penggunaan puzzle membuat pikiran anak lebih imajinatif dalam menghafal bentuk angka. Jika sering dilakukan maka anak akan terlatih untuk berasosiasi dalam berbagai hal.

Dengan melihat sisi kelebihan dan kekurangan dalam proses penelitian ini, dapat disimpulkan bahwa kemampuan anak dalam mengenal angka 1 - 10 di Homescooling ABCD dapat ditingkatkan dengan menggunakan media yang menarik salah satunya papan puzzle

\section{SIMPULAN}

Berdasarkan hasil penelitian dan pembahasan yang telah dilakukan dapat disimpulkan bahwa pembelajaran dengan media papan puzzle dapat meningkatkan kemampuan mengenal angka 1 - 10 di Homeschooling ABCD.

\section{SARAN}

Papan puzzle dipilih yang sesuai dengan karakteristik pembelajaran dan harus ada di lingkungan anak sehingga mudah dipahami oleh anak. Papan puzzle diusahakan semirip mungkin dengan bentuk angka yang diinginkan sehingga memudahkan proses asosiasi. Dilakukan perhatian yang lebih serius terhadap bentuk angka yang mirip dan kegiatan pembelajaran harus dilakukan

Diharapkan dapat menyediakan fasilitas untuk mendukung pembelajaran pengenalan angka dengan menggunakan media papan puzzle. 


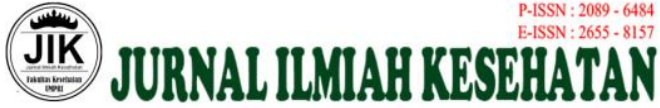

Vol 10 No 2 Juli 2021 | Page 69-76

\section{DAFTAR PUSTAKA}

Balitbang Kemenkes RI. (2013). Riset Kesehatan Dasar; RISKESDAS. Jakarta: Balitbang Kemenkes RI

Daryanto.(2012). Media Pembelajaran. Bandung: Sarana Tutorial Nurani Sejahtera.

Dina Indriana. (2011). Ragam Alat Bantu Media Pembelajaran. Yogyakarta: Diva Press.

Fitriyanti. (2015). Meningkatkan kemampuan mengenal angka 1 - 10 dengan media gambar asosiatif di kelompok B TK Budi Rahayu. Departemen Ilmu Kesehatan Anak, Fakultas Fakultas Ilmu Pendidikan Universitas Negeri Yogyakarta

Gunawan MAA, (2017). Hubungan Durasi Penggunaan Gawai Terhadap Perkembangan Sosial Anak Prasekolah di TK PGRI 33 Sumurboto Banyumanik Semarang. Tidak dipublikasikan, UNDIP

Laili U, (2017). Influence Of Gawai On Social Personal Of Early JURNAL KEBIDANAN Vol. 8 No. 1 October 2018 p- ISSN.2089-7669 e-ISSN. 2621-2870 64 Childhood. Proceeding of Surabaya International Health Conference, Juli 13-14, 2017

Nabila, Sarah dan Lisiswanti, Rika, (2017). Dampak Eksposur Layar Monitor Terhadap Gangguan Tidur Daan Tingkat Obesitas Pada Anak-Anak. Jurnal Majority, Vol.6 No.2 Maret 2017 Hal.73-78

Satori, Djam'an dan Aan Komariah, (2012). Metodologi Penelitian Kualitatif. Bandung :Alfabeta.

Warisyah, Y. (2015). Pentingnya Pendamping Dialogis Orang Tua Dalam Penggunaan Gawai Pada Anak Usia Dini. Makalah Disajikan Pada Seminar Nasional Diselenggarakan Universitas Muhammadiyah Ponorogo, Yogyakarta, Tanggal 7 November 